\title{
Article \\ Comparative Evaluation for an Improved Direct Instantaneous Torque Control Strategy of Switched Reluctance Motor Drives for Electric Vehicles
}

\author{
Mahmoud Hamouda 1,2,*(D), Amir Abdel Menaem ${ }^{3}$, Hegazy Rezk ${ }^{4,5}(\mathbb{D})$, Mohamed N. Ibrahim ${ }^{6,7,8}(\mathbb{D})$ \\ and László Számel ${ }^{2}$ (D)
}

1 Electrical Engineering Department, Mansoura University, 35516 Mansoura, Egypt

2 Department of Electric Power Engineering, Budapest University of Technology and Economics, H-1521 Budapest, Hungary; szamel.laszlo@vet.bme.hu

3 Department of Automated Electrical Systems, Ural Power Engineering Institute, Ural Federal University, 620002 Yekaterinburg, Russia; abdel.menaem@urfu.ru

4 College of Engineering at Wadi Addawaser, Prince Sattam Bin Abdulaziz University, Wadi Aldawaser 11991, Saudi Arabia; hegazy.hussien@mu.edu.eg

5 Electrical Engineering Department, Faculty of Engineering, Minia University, 61111 Minia, Egypt

6 Electrical Engineering Department, Kafrelshiekh University, 33511 Kafr El-Sheikh, Egypt; m.nabil@ugent.be

7 Department of Electromechanical, Systems and Metal Engineering, Ghent University, 9000 Ghent, Belgium

8 FlandersMake@UGent-Corelab EEDT-MP, 3001 Leuven, Belgium

* Correspondence: $\mathrm{m} \_$hamouda26@mans.edu.eg

Citation: Hamouda, M.; Abdel

Menaem, A.; Rezk, H.; Ibrahim, M.N.; Számel, L. Comparative Evaluation for an Improved Direct Instantaneous Torque Control Strategy of Switched Reluctance Motor Drives for Electric Vehicles. Mathematics 2021, 9, 302. https://doi.org/10.3390/math9040302

\section{Academic Editor:}

Alessandro Niccolai

Received: 30 December 2020

Accepted: 1 February 2021

Published: 4 February 2021

Publisher's Note: MDPI stays neutral with regard to jurisdictional claims in published maps and institutional affiliations.

Copyright: (c) 2021 by the authors. Licensee MDPI, Basel, Switzerland. This article is an open access article distributed under the terms and conditions of the Creative Commons Attribution (CC BY) license (https:// creativecommons.org/licenses/by/ $4.0 /)$.

\begin{abstract}
Due to the expected increase in the electric vehicles (EVs) sales and hence the increase of the price of rare-earth permanent magnets, the switched reluctance motors (SRMs) are gaining increasing research interest currently and in the future. The SRMs offer numerous advantages regarding their structure and converter topologies. However, they suffer from the high torque ripple and complex control algorithms. This paper presents an improved direct instantaneous torque control (DITC) strategy of SRMs for EVs. The improved DITC can fulfill the vehicle requirements. It involves a simple online torque estimator and a torque error compensator. The turn-on angle is defined analytically to achieve wide speed operation and maximum torque per ampere (MTPA) production. Moreover, the turn-off angles are optimized for minimum torque ripples and the highest efficiency. In addition, this paper provides a detailed comparison between the proposed DITC and the most applicable torque control techniques of SRMs for EVs, including indirect instantaneous torque control (IITC), using torque sharing function (TSF) strategy and average torque control (ATC). The results show the superior performance of the proposed DITC because it has the lowest torque ripples, the highest torque tor current ratio, and the best efficiency over the low and medium speed ranges. Moreover, the comparison shows the advantages of each control technique over the range of speed control. It provides a very clear overview to develop a universal control technique of SRM for EVs by merging two or more control techniques.
\end{abstract}

Keywords: switched reluctance motor; direct instantaneous torque control; numerical analysis; optimization

\section{Introduction}

Electric vehicles (EVs) are the way forward for green transportation and for establishing a low-carbon economy [1-3]. The simple and robust structure, low cost, less maintenance, high reliability, fault-tolerant, high efficiency, high-speed capability, and large constant power-speed ratio make switched reluctance motors (SRMs) a strong candidate with real chances on the market for vehicle propulsion [4-6].

SRMs do not suffer from the drawbacks noted in DC, induction, and permanent magnets (PMs) machine drives. They offer great robustness of construction. In addition, SRMs have none of the mechanical problems at high speeds that beset other drives. The 
lack of PMs or rotor winding also reduces cost and offers increased high-speed operation capability [1]. Furthermore, the SRM drives have a highly reliable converter topology. The stator windings are connected in series with the switches preventing the shoot-through faults to which the AC rotating field machine's converters are exposed $[7,8]$. The low rotor inertia allows high torque per inertia ratio and fast response. In addition, the robust rotor construction raises the maximum operating speed and the permissible rotor temperature. SRM has an inherent four-quadrant operation that meets the demands of EVs propulsion. However, the main obstacles that limit the usage of SRMs in high-performance variablespeed applications are the high torque ripple and the complicated control $[9,10]$.

The machine design, in the early stages, is used to reduce torque ripple. The machine design is effective only over a limited speed range [11]. A wider operating range, but still limited, can be achieved by current or flux profiling [12,13]. However, the profiling techniques require time-consuming pre-calculations to find the optimal current or flux profiles. Therefore, the instantaneous torque control (ITC) is gaining interest in the areas of torque ripple reduction for SRM drives [14]. The indirect ITC (IITC) is an effective strategy for torque ripple reduction in SRMs. It uses a torque sharing function (TSF) to distribute torque between motor phases. In [14], the minimization of both the copper loss and the derivatives of current references were the main objective of the used offline TSF. However, the limitations of offline TSF are treated using an online TSF [15]. A proportional and integral compensator with torque error is added to the torque reference. The structure of TSF, in addition to the torque estimator, complicates the control algorithm. In [16], the torque-speed capability was improved using an adaptive TSF. Over the speed range, the turn-on angles were controlled without adjustment of the shape of TSF. However, the TSF had a lower torque to current rations. In [17], the phase current was compensated in the demagnetizing period to reduce torque ripple and extend speed range. In [18], the reference current shape was modified to reduce the current tracking error. Despite the effectiveness of TSF for torque ripple reduction in SRM drives, it is meant only for low-speed operation. In addition, it used a torque inverse model that is not a straightforward transformation. The torque is a function of position and current. Developing analytical expressions for real-time implementation is not an easy task [19]. Moreover, the fitting accuracy affects the control performance. Look-up tables can be employed for such problems but require additional memory for data storage [20].

On the other hand, the average torque control (ATC) is an advantageous solution for EVs. It has many advantages compared to ITC [21-23]. ATC has a much simple structure; it has a higher torque per ampere ratio, needs a discrete rotor position, and can be used for the entire speed range. However, ATC has a relatively large amount of torque ripple compared to ITC because it controls only the turn-on $\left(\theta_{\text {on }}\right)$ and turn-off $\left(\theta_{\text {off }}\right)$ angles. The optimization of $\theta_{\text {on }}$ and $\theta_{\text {off }}$ angles is achieved mainly for torque ripple reduction, efficiency improvement, or copper loss minimization. In [24], the maximization of average torque per ampere was aimed. The torque ripple that does not suit several applications, including EVs, was ignored. Therefore, secondary objectives, including torque-ripple reduction, copper losses minimization, and efficiency improvement, were included $[23,25,26]$.

On the other hand, the direct ITC (DITC) is an effective solution for torque ripple reduction of SRM drives. It controls the torque directly because it employs a hysteresis torque controller. In [27], the DITC of SRM was introduced. The terminal quantities (flux and current) were used to estimate the instantaneous motor torque. However, the integration of phase voltage for flux calculation limited the operation of DITC for low speeds. In addition, the errors in signal processing, phase resistance, and analog to digital converters cause an integration offset. Moreover, the built DITC is effective only till base speed as long as the back EMF is less than or equal to DC voltage. Furthermore, fixed switching angles were used, which affects the generated torque and efficiency.

In [28], the low-speed limits were handled by the online estimation of motor torque as a function of current and rotor position in the form of lookup tables. However, the lookup tables require large memory to store data. In addition, the effect of commutation angles 
was not included. In [29], a simplified DITC of SRM was achieved. The inner control loops of current and flux were excluded, which eliminates the fault-tolerant advantage of SRM converter topologies. Moreover, the torque was estimated using flux and current data in the form of lookup tables. These tables require large memory to store data and have the problems of flux estimation errors in [27]. In [30], the torque ripple was reduced by adding a PI controller before the torque hysteresis regulator. Three conduction zones were defined, which complicated the control algorithm. Moreover, more fluctuations of DC voltage are expected due to energy return in zone 1. In [31,32], a five-level converter was used to reduce the torque ripple of SRM drives based on DITC. However, the dynamic balance of DC-link capacitor voltage has to be considered, and appropriate switching states have to be generated. In [33], a multi-level power converter was proposed based on a modular converter and three-level switch module. The proposed converter complicates the control algorithm and increases the cost and dissipated heat. In [34], an optimized DITC was achieved based on an adaptive dynamic commutation strategy. The turn-on angle was modified by a torque error regulator. The turn-off angle was defined according to the phase current endpoint detector. However, due to continuous changes of operating conditions in EVs, the variation of commutation angles does not suit their applications very well. Moreover, the maximum torque per ampere (MTPA) production is not guaranteed by forcing phase current to decay at the aligned position using the endpoint detector.

This paper presents an improved DITC strategy of SRMs for EVs. The proposed control uses a simple online torque estimator and calculates the instantaneous motor torque as a function of current and position to avoid flux integration errors and improve the low-speed operation capability. Furthermore, a torque error compensator is added to compensate for the torque ripple. This, in turn, reduces the torque ripple and extends the smooth torque-speed range. Moreover, the control parameters are optimized for the best performance including maximum torque per ampere (MTPA), minimum torque ripples, extended speed operation, and high efficiency. First, the turn-on $\left(\theta_{o n}\right)$ angle is calculated analytically for the MTPA production. Second, an optimization-based method is set for the turn-off $\left(\theta_{\text {off }}\right)$ angle. The optimization aims to achieve the minimum torque ripples and the maximum efficiency at each operating point. The cost function is calculated within the steady-state machine simulation model. The required torque to current conversions is obtained from the finite element analysis (FEA) data of studied 8/6 SRM. Furthermore, this paper provides a detailed comparison between the proposed DITC and the most applicable torque control techniques of SRMs for EVs including the IITC and the ATC. Each control strategy (IITC and ATC) is optimized for the best performance. The optimization details are included in the next sections.

The paper organization is as follows: Section 2 shows the machine modeling and performance indices. The proposed control, the optimization problem, the solution method, and the optimization results are involved in Section 3. The simulation verification is presented in Section 4. Finally, Section 5 provides the conclusions drawn from this research.

\section{Machine Modeling}

Due to the double saliency of SRMs, the flux-linkage $\lambda(i, \theta)$, inductance $L(i, \theta)$, and torque $T(i, \theta)$ have nonlinear relations with current $(i)$ and position $(\theta)$. Equation (1) shows the voltage equation. The electromagnetic torque of $k^{\text {th }}$ phase $\left(T_{k}\right)$ and the total electromagnetic torque ( $\left.T_{e}\right)$ with $q$-phases can be represented by Equation (2). The mechanical dynamics is shown by Equation (3) [25].

$$
\begin{gathered}
v_{k}=R i_{k}+\frac{\partial \lambda_{k}\left(i_{k}, \theta\right)}{\partial t} ; \quad \lambda_{k}\left(i_{k}, \theta\right)=\int\left(v_{k}-R i_{k}\right) d t \\
T_{k}=\frac{1}{2} \frac{\partial L_{k}}{\partial \theta} i_{k}^{2} ; \quad T_{e}=\sum_{k=1}^{q} T_{k} \\
T_{e}-T_{L}=B \omega+J \frac{d \omega}{d t}
\end{gathered}
$$


where $J$ is the inertia, $B$ is the frictional coefficient, $\omega$ is the rotor speed, and $T_{L}$ is the load torque.

The finite element method (FEM) is employed to generate the magnetic characteristics of the studied 8/6 SRM. The FEM data are used in form of look-up tables to build the machine model in MATLAB/Simulink [25]. The studied motor is $4 \mathrm{~kW}, 1500 \mathrm{r} / \mathrm{min}$, $600 \mathrm{~V}, 8 / 6$ poles, 4 phases SRM. The flux linkage and torque characteristics are shown in Figure $1 \mathrm{a}, \mathrm{b}$, respectively. These figures show only a few curves for simplification, while the complete flux and torque characteristics are calculated for current [0:1:50]A and position of $[0: 0.5: 30]^{\circ}$. The unaligned and aligned positions are defined by angle $\theta=0^{\circ}$ and angle $\theta=30^{\circ}$, respectively. As seen, both the flux and torque have highly nonlinear characteristics.

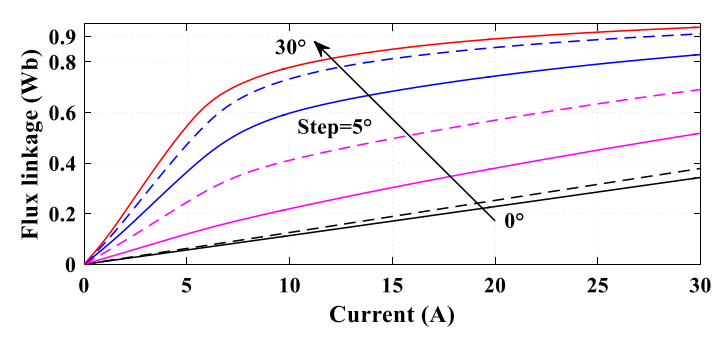

(a)

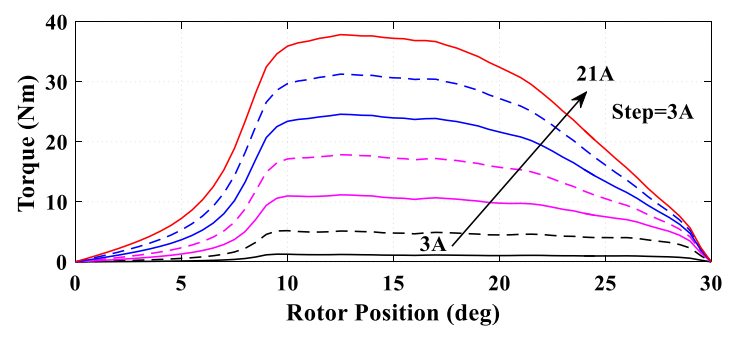

(b)

Figure 1. The finite element method (FEM)-calculated characteristics-(a) flux linkage and (b) torque.

\section{Performance Indices}

The performance indices include the calculation of average torque $\left(T_{a v}\right)$, torque ripple $\left(T_{r}\right)$, average supply current $\left(I_{a v}\right)$, efficiency $(\eta)$, mechanical output power $\left(P_{m}\right)$, the total harmonic distortion (THD) of phase current, switching frequency of converter $\left(f_{s w}\right)$, and root mean square (RMS) supply current $\left(I_{R M S}\right)[4,10,29]$.

The torque ripple $\left(T_{r}\right)$ of SRM is calculated from the maximum and minimum instantaneous torque values ( $T_{\max }$ and $T_{\min }$ ) as expressed by Equation (4). The average torque $\left(T_{a v}\right)$ is calculated over one electric cycle $(\tau)$.

$$
T_{r}=\frac{T_{\max }-T_{\min }}{T_{a v}} ; \quad T_{a v}=\frac{1}{\tau} \int_{0}^{\tau} T_{e}(t) d t
$$

The efficiency $(\eta)$ and average supply current $\left(I_{a v}\right)$ can be expressed as

$$
\eta=\frac{\omega T_{a v}}{V_{D C} I_{a v}} ; \quad I_{a v}=\frac{1}{\tau} \int_{0}^{\tau} i_{s}(t) d t
$$

The mechanical output power can be estimated as follows:

$$
P_{m}=T_{a v}(t) \cdot \omega(t)
$$

Equation (7) is the most adopted for spectrum performance for THD of phase current [35].

$$
T H D=\sqrt{\frac{I_{r m s}^{2}-I_{1, r m s}^{2}}{I_{1, r m s}^{2}}}
$$

where $I_{1, r m s}$ represents the root mean square (RMS) value of the fundamental component of phase current. $I_{r m s}$ depicts the RMS value of phase current.

The RMS supply current $\left(I_{R M S}\right)$ and switching frequency $\left(f_{s w}\right)$ are seen by Equations (8) and (9), respectively.

$$
I_{R M S}=\sqrt{\frac{1}{\tau} \int_{0}^{\tau} i_{k}^{2}(t) d t}
$$




$$
f_{s w}=\frac{1}{\tau} \int_{0}^{\tau} N_{T} d t
$$

where $N_{T}$ is the total number of switching of IGBTs over one electric period $\tau$.

\section{The Proposed Direct Instantaneous Torque Control (DITC)}

Figure 2 shows the block diagram of the proposed DITC. It has an outer loop speed controller, middle loop torque controller, and inner loop current controller. The speed controller outputs a reference torque signal $\left(T_{r e f}\right)$. The torque error $(\Delta T)$ is the difference between $T_{\text {ref }}$ and the estimated actual motor torque $\left(T_{\text {est }}\right) . \Delta T$ is processed through a hysteresis torque controller that outputs the state signals. The reference current $\left(i_{\text {ref }}\right)$ is calculated as a function of $T_{r e f}$ using a proposed torque to the current conversion scheme. In addition, a torque ripple compensator is added, it uses a PI controller (probably a P controller) to compensate for the torque errors. Moreover, the commutation angles $\left(\theta_{\text {on }}\right.$ and $\left.\theta_{o f f}\right)$ are estimated online for the best performance. A simple online torque estimator using third-order polynomial is used to avoid the required big memory for the look-up tables. The torque is estimated as a function of phase current and position, the details are included in [36].

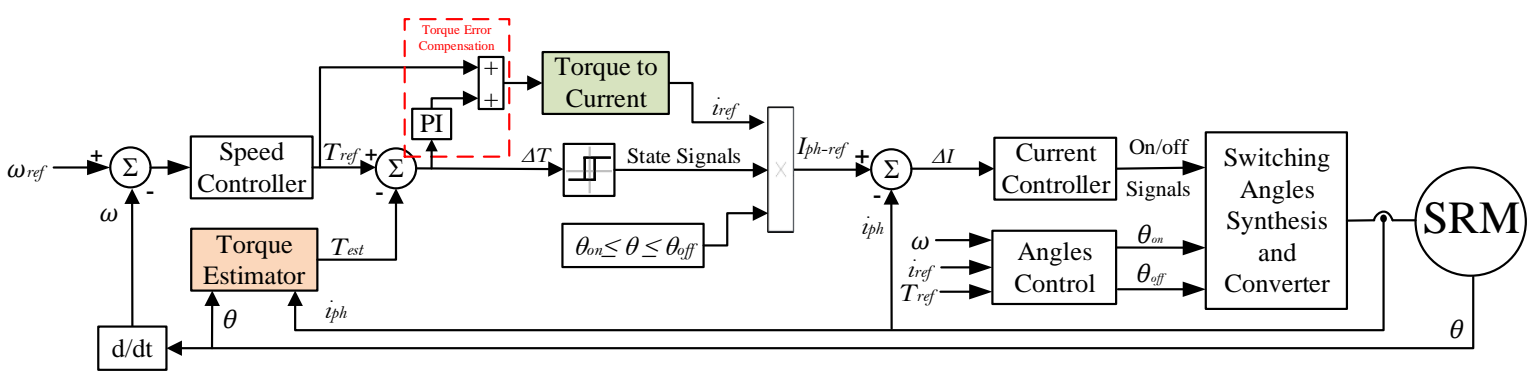

Figure 2. Block diagram of the proposed direct instantaneous torque control (DITC).

\subsection{Torque to Current Conversion}

Due to the high nonlinear torque characteristics of SRMs, the torque to current conversion is not a feedforward transformation. For a precise torque to current conversion, the control algorithm will be much complicated. However, in this case, the reference torque signal $\left(T_{\text {ref }}\right)$ is required to be converted to a reference current signal $\left(i_{\text {ref }}\right)$. This conversation can be implemented simply using polynomial fitting. This, in turn, helps to simplify the overall control algorithm.

For $8 / 6$ SRM, the ideal conduction angle is $15^{\circ}$. Each phase will produce torque over $15^{\circ}$. Moreover, the conditions for maximum torque per ampere (MTPA) include the peak phase current to reach its reference value at the end of the minimum inductance zone (angle $\theta_{m}$ ) [37]. Therefore, for the best torque production is achieved over a period $\left[\theta_{m}, \theta_{m}+15^{\circ}\right]$, as shown in Figure 3a. for each current magnitude, the average torque can be estimated from the FEM-calculated torque data. Then, polynomial fitting can be simply carried out, as seen in Figure 3b.

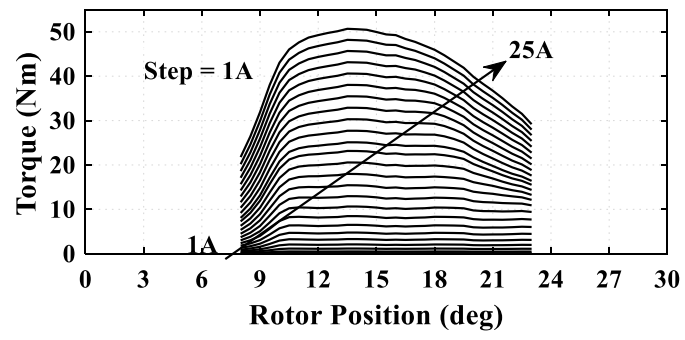

(a)

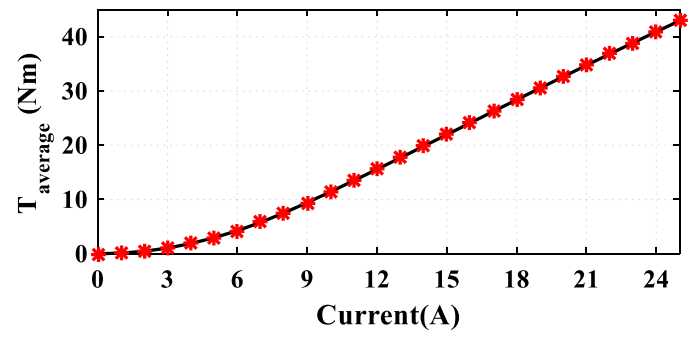

(b)

Figure 3. Torque to current conversion-(a) torque curves over most efficient $15^{\circ}$ and (b) torque fitting. 


\subsection{Switching Angles Optimization}

To achieve the MTPA conditions, the turn-on $\left(\theta_{\text {on }}\right)$ angle is calculated using Equation (10) [37]. This Equation determines the optimum $\theta_{\text {on }}$ to provide the most efficient operation. It considers accurately the effect of back-emf voltage at low and high speeds.

$$
\theta_{o n}=\theta_{m}+\frac{L_{e f f}(i, \theta)}{R+k_{b-e f f} \omega} \ln \left(1-i_{r e f} \frac{R+k_{b-e f f} \omega}{V_{D C}}\right)
$$

where $R$ is the phase resistance, and $V_{D C}$ is the dc voltage.

On the other hand, an optimization problem is set for the turn-off $\left(\theta_{\text {off }}\right)$ angle to provide the minimum torque ripples, the lowest copper losses, and the highest efficiency. The objective function is provided by Equation (11) with a combination of torque ripple $\left(T_{r}\right)$, copper losses $\left(P_{c u}\right)$, and efficiency $(\eta)$.

$$
\begin{aligned}
F_{o b j}\left(\theta_{o f f}\right)= & \min \left(w_{r} \frac{T_{r}}{T_{r b}}+w_{c u} \frac{P_{c u}}{P_{c u b}}+w_{\eta} \frac{\eta_{b}}{\eta}\right) \\
& w_{r}+w_{c u}+w_{\eta}=1
\end{aligned}
$$

where $F_{o b j}$ is the objective function. $T_{r b}$ is the base value of torque ripples. $P_{c u b}$ is the base value of the copper loss. $\eta_{b}$ is the base value of efficiency. $w_{r}$ is the weight factor of torque ripples. $w_{c u}$ is the weight factor of copper loss. $\eta_{r}$ is the weight factor of efficiency.

Figure 4 shows the flowchart of the developed searching algorithm. At each operating point, defined by the reference torque and speed, the turn-off angle $\left(\theta_{\text {off }}\right)$ is changed in small steps. The simulation model is employed to calculate the torque ripple, copper loss, and efficiency at each step. At the end of the search, the minimum torque ripple, the minimum copper losses, and the maximum efficiency are defined as the base values $\left(T_{r b}, P_{c u b}\right.$, and $\left.\eta_{b}\right)$. The turn-off angle $\left(\theta_{\text {off }}\right)$ is varied from $\theta_{\text {off-min }}=15^{\circ}$ to $\theta_{\text {off-max }}=28^{\circ}$ in steps of $0.2^{\circ}$. Then, the optimum angle is defined using Equation (11). This procedure is repeated several times according to the desired speeds and torque levels. In this paper, the torque is changed with a step of $2 \mathrm{Nm}$. The speed step is taken as $200 \mathrm{r} / \mathrm{min}$. Figure 5 presents the optimum turn-off angles. As noted, for a given motor speed, the turn-off angle is almost constant. It decreases with increasing motor speed.
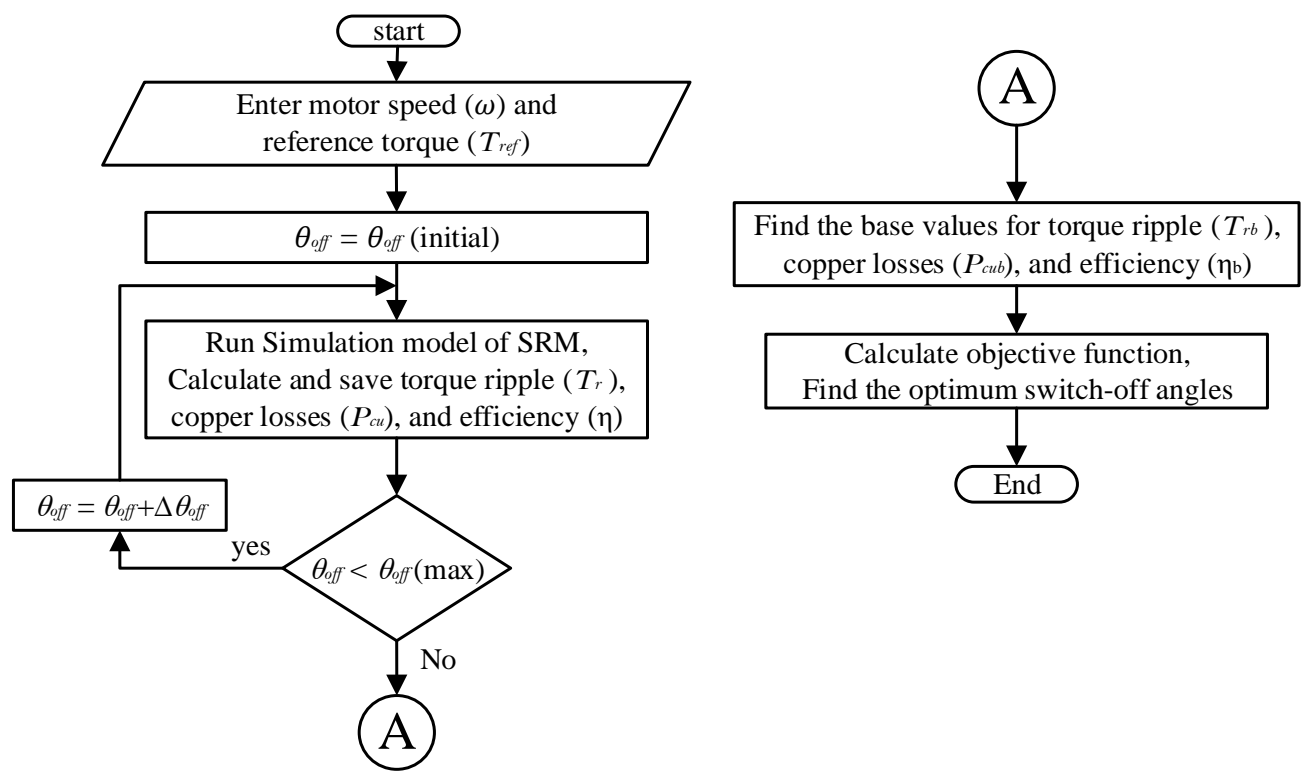

Figure 4. The flowchart of the searching algorithm. 


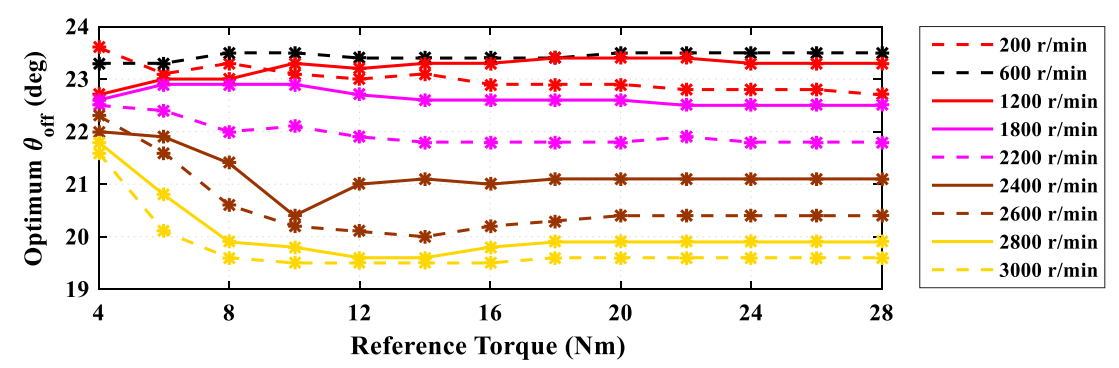

Figure 5. The optimized turn-off angles.

The weight factors $\left(w_{r}, w_{c u}\right.$, and $\left.\eta_{r}\right)$ are chosen according to the desired level of optimization. The weighting factors are $w_{r}=0.4, w_{c u}=0.3$, and $\eta_{r}=0.3$.

\subsection{Simulation Results of the Proposed DITC}

The simulation results of the proposed DITC are provided in Figure 6. A sudden change of the commanded reference speed is made at 0.3 and $0.6 \mathrm{sec}$ (Figure 6a). The load torque has a constant value of $17 \mathrm{Nm}$. The motor can track the desired speed efficiently. The generated torque has a very good profile as illustrated in Figure $6 \mathrm{~b}$. Till speed of $2000 \mathrm{r} / \mathrm{min}$, the amount of torque ripple is very minor (Figure $6 \mathrm{c}$ ); as the motor speed increases, the torque ripples increase. The $\theta_{\text {on }}$ and $\theta_{\text {off }}$ angle have smooth variation along with the speed and torque level, as shown in Figure $6 \mathrm{~d}$,e, respectively. The mechanical output power and the total motor efficiency are provided in Figure 6f,g, respectively. The system has very good efficiency. As the motor speed increases, the efficiency also increases.

\section{The Other Torque Control Techniques of SRM}

This section involves the most applicable torque control techniques of SRM drives for EVs. It provides the ATC, followed by the IITC.

\subsection{Average Torque Control (ATC)}

The block diagram of the adopted ATC is shown in Figure 7 [22,23]. The outer loop speed control provides the reference torque $\left(T_{\text {ref }}\right)$. The torque error $(\Delta T)$ is processed by the torque controller (PI) that outputs $i_{\text {ref. }}$. The switching angles $\left(\theta_{o n}\right.$ and $\left.\theta_{\text {off }}\right)$ are estimated as functions of motor speed $(\mathrm{w})$ and reference torque/current.

\subsubsection{Switching Angles Optimization}

The optimization aims to achieve the lowest torque ripple, the lowest copper losses, and the highest efficiency. Three groups multi-objective optimization function is used as follows:

$$
\begin{gathered}
F_{o b j}\left(\theta_{o n}, \theta_{o f f}\right)=\min \left(w_{r} \frac{T_{r}}{T_{r b}}+w_{c u} \frac{P_{c u}}{P_{c u b}}+w_{\eta} \frac{\eta_{b}}{\eta}\right) \\
w_{r}+w_{c u}+w_{\eta}=1
\end{gathered}
$$

subject to

$$
\theta_{o n}^{\min } \leq \theta_{o n} \leq \theta_{o n}^{\max } ; \quad \theta_{o f f}^{\min } \leq \theta_{o f f} \leq \theta_{o f f}^{\max }
$$

where $\theta_{o n}^{\min }$ and $\theta_{o n}^{\max }$ are the minimum and the maximum limits of the $\theta_{o n}$, respectively. $\theta_{o f f}^{\min }$ and $\theta_{o f f}^{\max }$ are the minimum and the maximum limits of the $\theta_{\text {off }}$, respectively.

The weight factors for $\left(w_{r}, w_{c u}\right.$, and $\left.w_{\eta}\right)$ are determined according to the required optimization level. Due to the higher torque ripple of ATC, greater importance is directed to reduce torque ripples. The weight factors are set to $w_{r}=0.6, w_{c u}=0.2$, and $w_{\eta}=0.2$. 


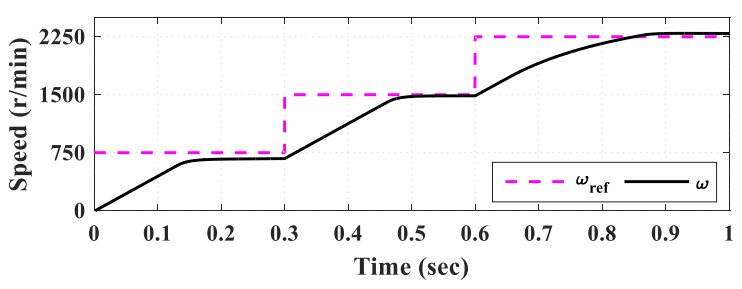

(a)

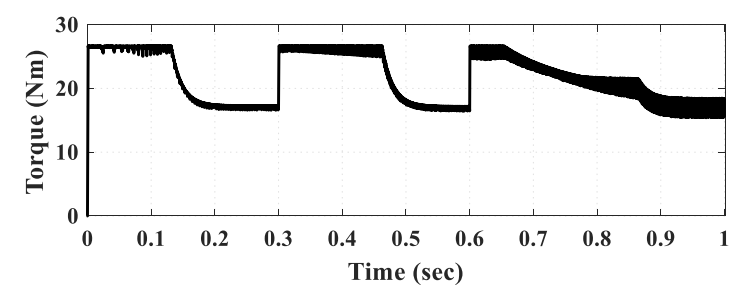

(b)

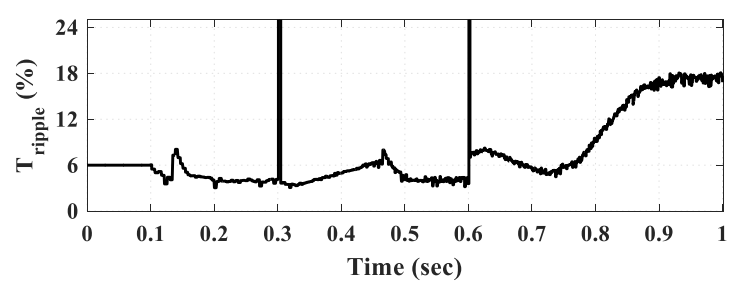

(c)

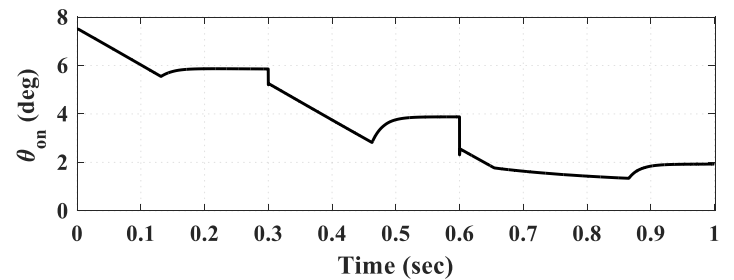

(d)

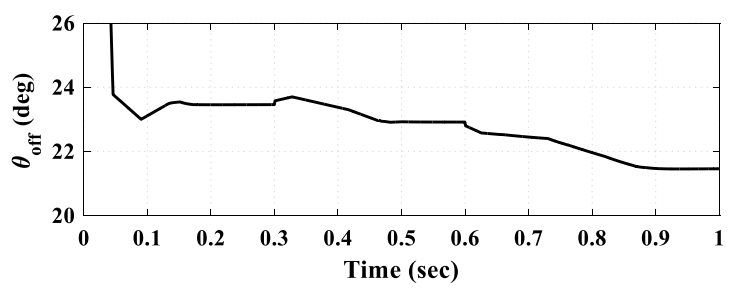

(e)

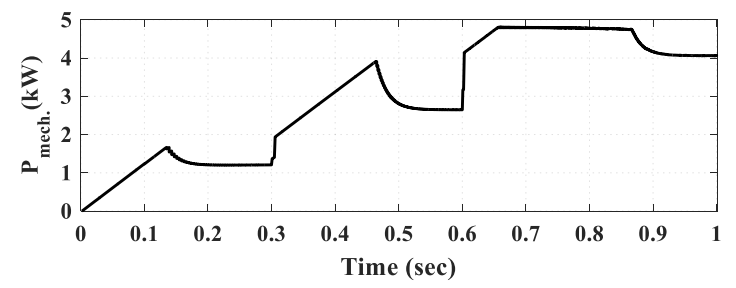

(f)

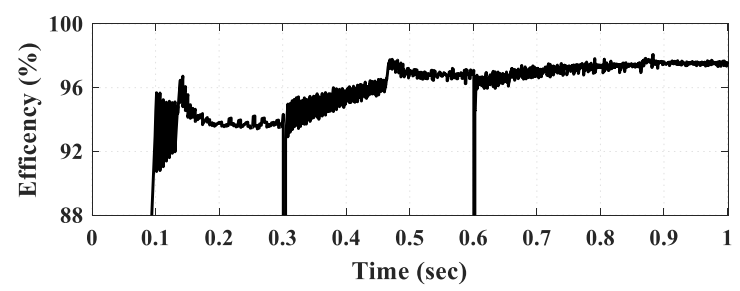

(g)

Figure 6. The simulation results for DITC-(a) motor speed, (b) total torque, (c) torque ripple, (d) turn-on angle, (e) turn-off angle, (f) output power, and (g) efficiency.

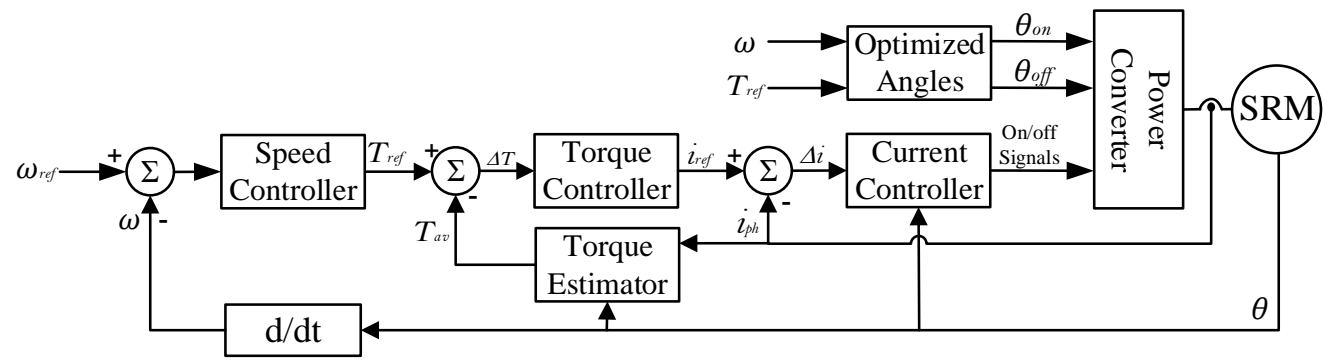

Figure 7. Block diagram of average torque control (ATC) technique.

\subsubsection{Simulation Results of ATC}

The simulation results for the proposed ATC are presented in Figure 8. A sudden change of the commanded reference speed is made at $0.4 \mathrm{sec}$ and $0.9 \mathrm{sec}$ (Figure 8a). The load torque has a constant value of $17 \mathrm{Nm}$. The motor can track the desired speed efficiently. The generated torque has a good profile as illustrated in Figure $8 \mathrm{~b}$. In general, as the motor speed increases, the torque ripples increase, as seen in Figure 8c. As seen, the torque ripple is high at very low speed. The $\theta_{\text {on }}$ and $\theta_{\text {off }}$ angles have adaptive and smooth 
variations along with motor speed and torque level, as shown in Figure $8 \mathrm{~d}$,e, respectively. The mechanical output power and the total motor efficiency are presented in Figure 8f,g, respectively. The system has very good efficiency, especially at higher speeds.

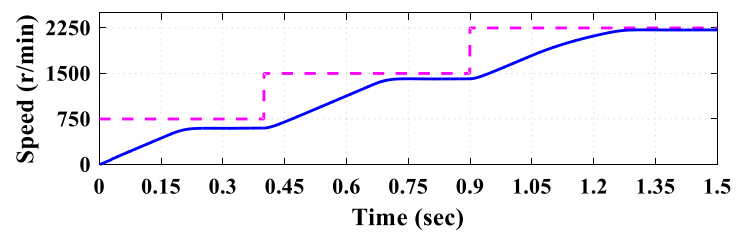

(a)

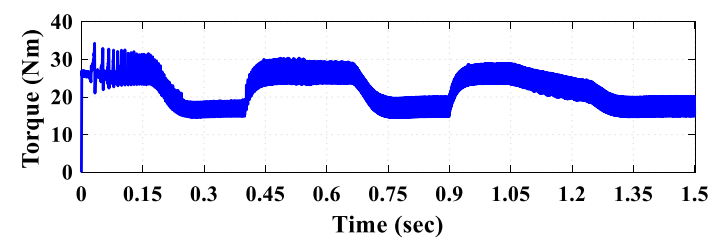

(b)

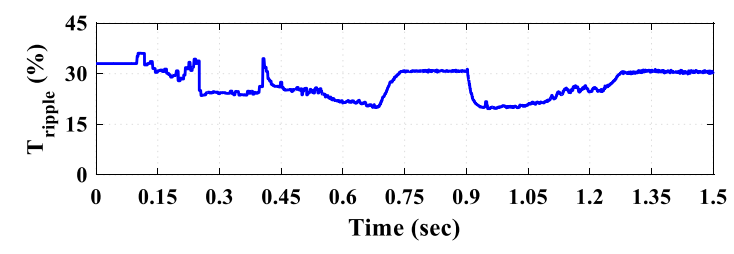

(c)

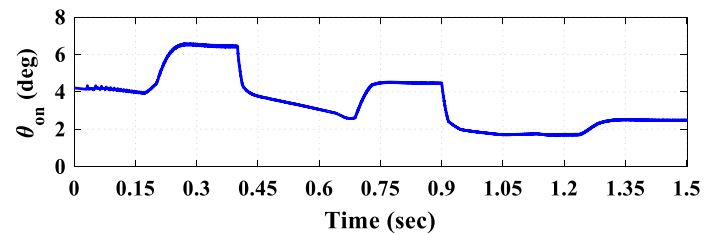

(d)

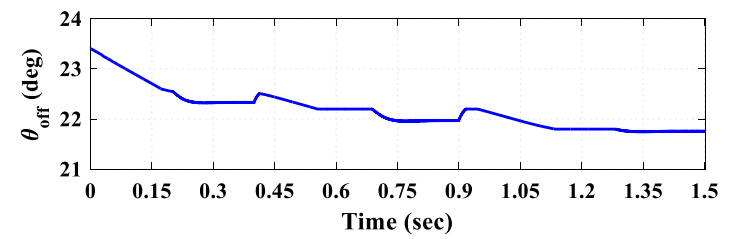

(e)

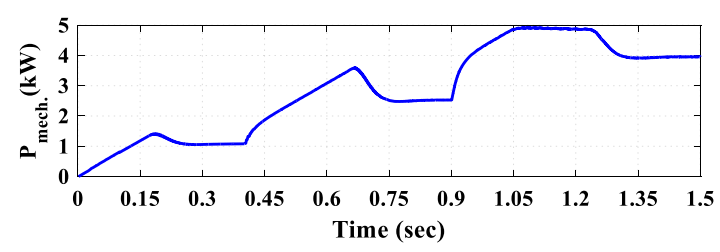

(f)

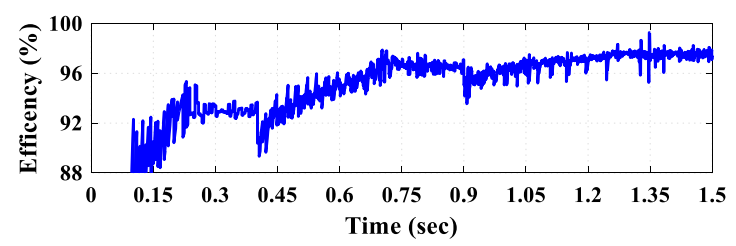

(g)

Figure 8. The simulation results for ATC-(a) motor speed, (b) total torque, (c) torque ripple, (d) turn-on angle, (e) turn-off angle, (f) output power, and (g) efficiency.

\subsection{Indirect Instantaneous Torque Control (IITC)}

The block diagram of the IITC is presented in Figure 9. It has an outer loop speed controller and an inner loop current controller. The middle loop torque controller contains a TSF and torque inverse model $i(T, \theta)$. Moreover, the MTPA is achieved through the proper estimation of turn-on angle $\left(\theta_{o n}\right)$ using Equation (10). The torque to current conversion is also used here. Furthermore, a torque compensation is carried out to compensate for the torque ripple. The torque error $(\Delta T)$ is processed within the TSF to extend the operating speed range. The modified TSF is provided by Equation (16). The torque error is compensated with the incoming phase as it has the lower absolute changing rate of flux linkage with rotor position.

$$
\operatorname{TSF}(\theta)=\left\{\begin{array}{c}
0, \quad \text { if }\left(0 \leq \theta \leq \theta_{o n}\right) \\
\frac{T_{e}}{2}-\frac{T_{e}}{2} \cos \frac{\pi}{\theta_{o v}}\left(\theta-\theta_{o n}\right)+\Delta T, \quad \text { if }\left(\theta_{o n} \leq \theta \leq \theta_{o n}+\theta_{o v}\right) \\
T_{e}+\Delta T, \quad \text { if }\left(\theta_{o n}+\theta_{o v} \leq \theta \leq \theta_{o f f}\right) \\
T_{e}-\left(\frac{T_{e}}{2}-\frac{T_{e}}{2} \cos \frac{\pi}{\theta_{o v}}\left(\theta-\theta_{o n}\right)\right), \quad \text { if }\left(\theta_{o f f} \leq \theta \leq \theta_{o f f}+\theta_{o v}\right) \\
0, \quad \text { if }\left(\theta_{o f f}+\theta_{o v} \leq \theta \leq \theta_{p}\right)
\end{array}\right.
$$

where $\theta_{p}$ is the rotor period. $\theta_{o v}$ is the over-lap angle $\left(\theta_{o v} \leq 0.5 \theta_{p}-\theta_{o f f}\right)$. 


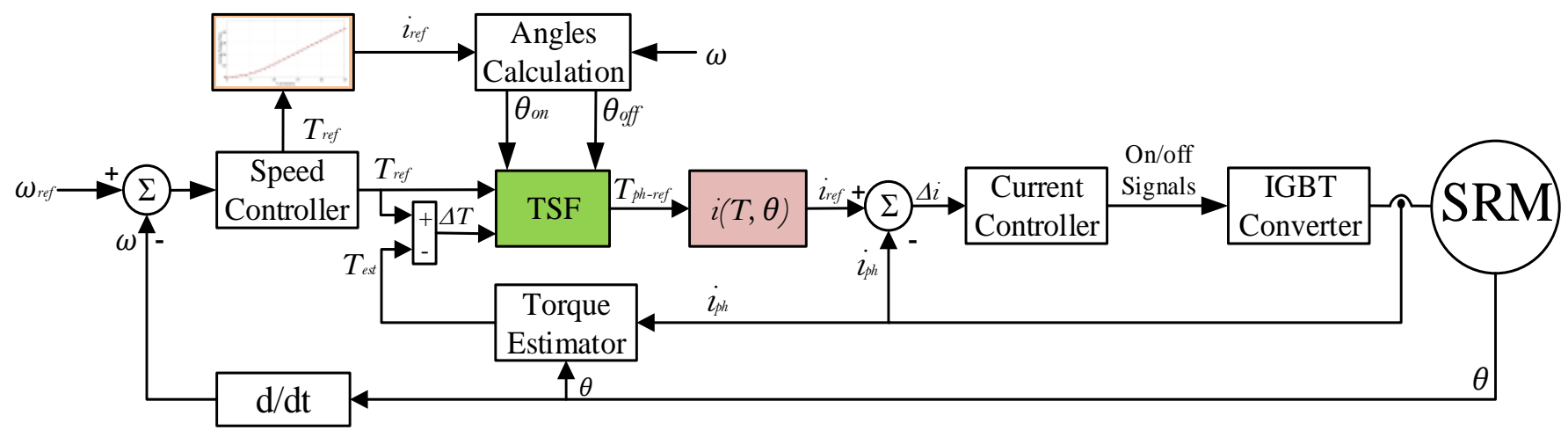

Figure 9. Block diagram of indirect instantaneous torque control (IITC) scheme.

Simulation Results of IITC

The simulation results for the proposed IITC are presented in Figure 10. A sudden change of the commanded reference speed is made at $0.3 \mathrm{sec}$ and $0.6 \mathrm{sec}$ (Figure 10a). The load torque has a constant value of $17 \mathrm{Nm}$. The motor can track the desired speed efficiently. The generated torque has a very good profile, as illustrated in Figure 10b. At low speed (below the base speed of $1500 \mathrm{r} / \mathrm{min}$ ), the amount of torque ripple is very minor. As the motor speed increases, the torque ripples increase, as seen in Figure 10c. The $\theta_{\text {on }}$ angle has a smooth variation along with the speed and torque level, as shown in Figure 10d. The smooth change means lower disturbance and less noise. The mechanical output power and the total motor efficiency are presented in Figure 10e,f, respectively. The system has very good efficiency, especially at higher speeds.

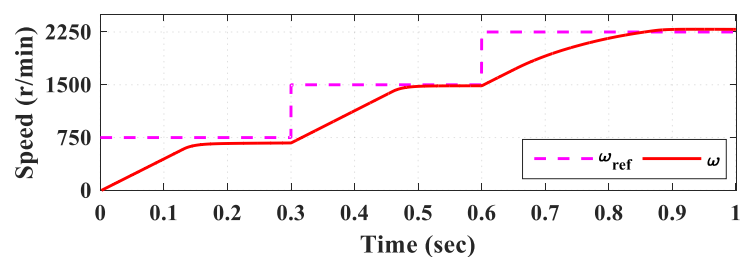

(a)

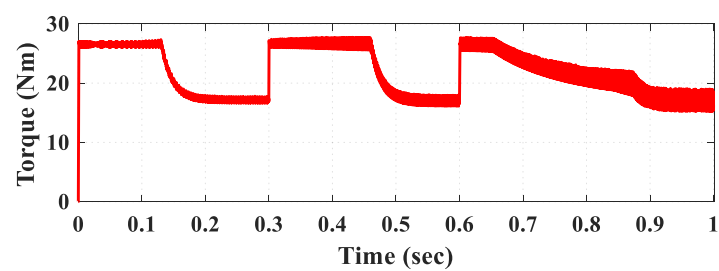

(b)

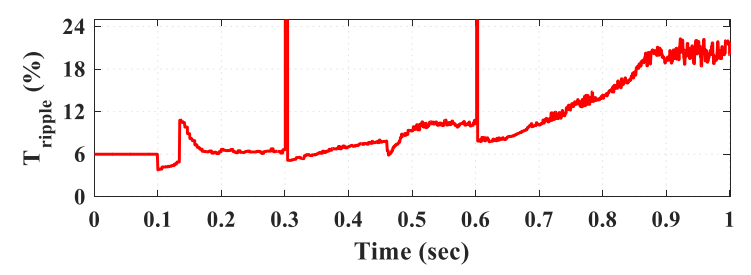

(c)

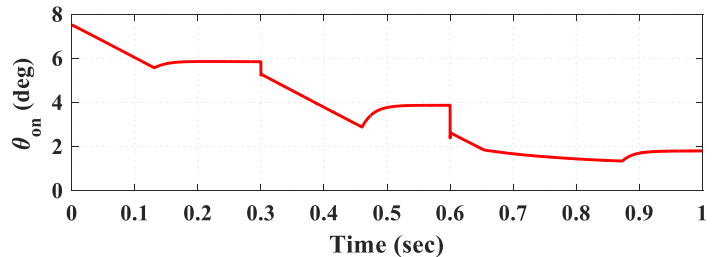

(d)

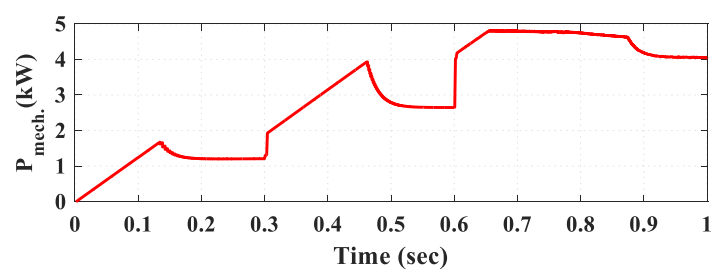

(e)

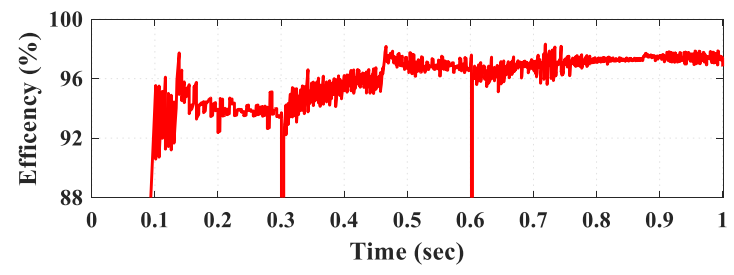

(f)

Figure 10. The simulation results for IITC-(a) motor speed, (b) total torque, (c) torque ripple, (d) turn-on angle, (e) output power, and (f) efficiency. 


\section{Comparative Analysis and Discussion}

To develop the best control technique of SRMs for EV applications, a comparative study with a detailed analysis of control performance is essential to gain the benefits of each technique. This comparative study includes the DITC, the TSF with MTPA and ripple compensation, and the ATC.

The study was conducted under variable loading conditions that represent the actual EV load. The parameters for the simulated EV are included in [1]. The study was also achieved under the full load conditions because EVs have a continuous change in operating point. Therefore, the motor will be under the full load conditions in the acceleration times.

\subsection{Under EV Loading}

Figure 11 shows the steady-state characteristics under EV loading conditions. The load torque proportionally increases with motor speed, as shown in Figure 11a. As noted, the ATC has the capability to provide higher torque production under high speeds (beyond $2200 \mathrm{r} / \mathrm{min}$ ). The DITC has the lowest torque ripples till the speed of $2500 \mathrm{r} / \mathrm{min}$, as illustrated in Figure 11b. After that speed, the ATC provides the lowest torque ripples. The DITC has the highest Tav $/ I_{R M S}$ ratio till the speed of $2200 \mathrm{r} / \mathrm{min}$, after that, the ATC provides the best Tav $/ I_{R M S}$ ratio (Figure 11c). The ATC provides the lowest switching converter frequency, as presented in Figure $11 \mathrm{~d}$. The maximum achievable switching frequency is less than $10 \mathrm{kHz}$ that fits most of the industrial applications. The IITC provides the lowest THD of phase current, followed by DITC and then ATC, as illustrated by Figure 11e. After $2500 \mathrm{r} / \mathrm{min}$, the ATC yields the lowest THD of phase current. As seen in Figure 11f, the DITC and ATC have the lowest $d \lambda / d t$. The efficiency curve is shown in Figure 11g. The DITC and ATC have higher efficiencies (almost the same) under low speeds (see Figure 11h), but the ATC provides higher efficiency.

\subsection{Under Full Load Conditions}

Figure 12 shows the steady-state characteristics under full load conditions. The motor is loaded with a constant load torque of $26 \mathrm{Nm}$ until it reaches the base speed ( $1500 \mathrm{r} / \mathrm{min})$ and then the torque decreases inversely with speed, as shown in Figure 12a. In general, the ATC has the capability to provide higher torque production at high speeds. The DITC has the lowest torque ripple at low speeds, while the ATC has a lower torque ripple at high speeds (Figure 12b). The best Tav/I RMS ratio is obtained by the DITC (Figure 12c). The IITC shows a higher switching frequency for low speeds (Figure 12d) compared to Figure 11d. The IITC provides the lowest THD for phase current, followed by ATC and then DITC, as seen in Figure 12e. Figure 12f shows the efficiency curves. As noted, the DITC has the best efficiency at low speeds, while the ATC provides the highest efficiency at high speeds.

\subsection{The Steady-State Torque Curves}

The steady-state torque curves under different operating speeds are illustrated in Figure 13. As observed, the DITC has the smoothest torque profile and hence the lower torque ripple. Despite the higher torque ripples of ATC, its torque profile seems very smooth especially at low speeds, as shown in Figure 13a,b. As the speed increases, the torque ripple also increases. After $2000 \mathrm{r} / \mathrm{min}$, the torque ripple appears even with DITC and TSF, as seen in Figure 13c,d. 


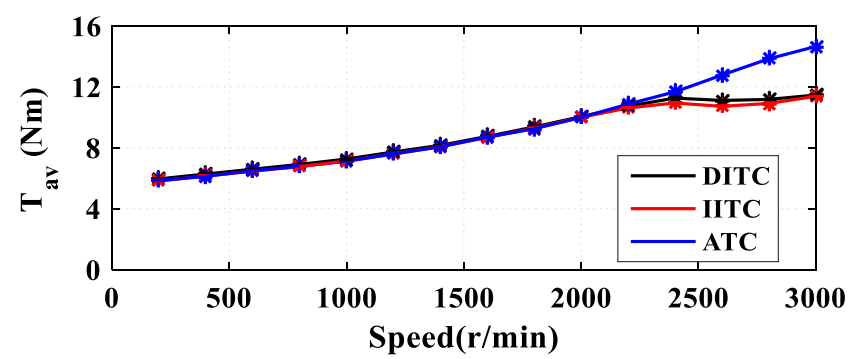

(a)

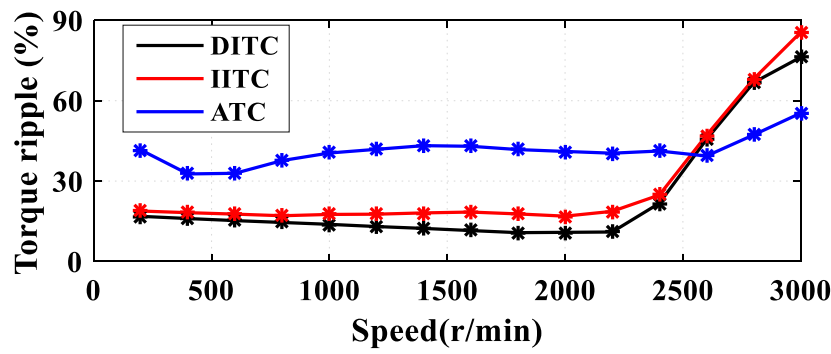

(b)

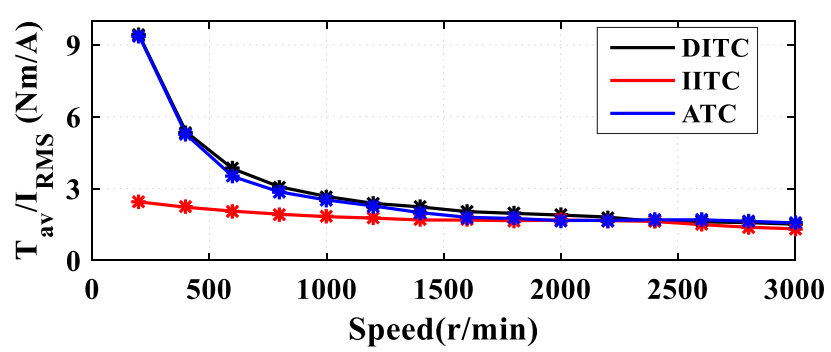

(c)

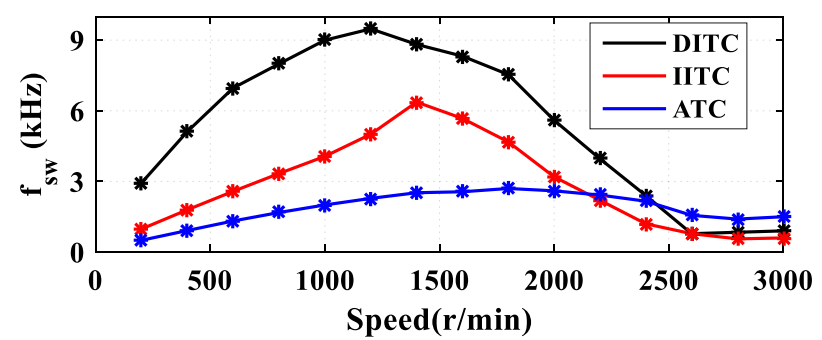

(d)

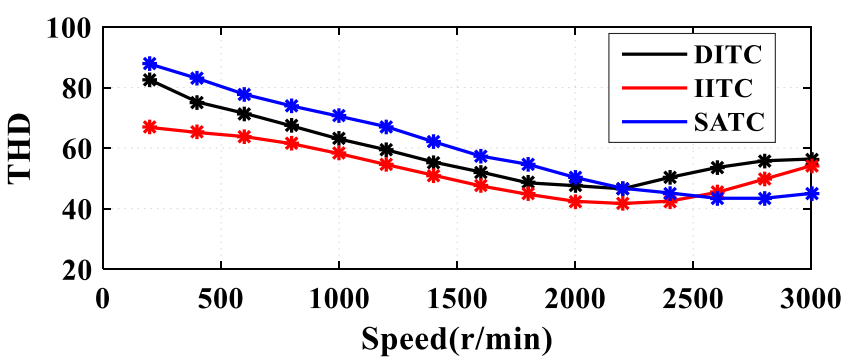

(e)

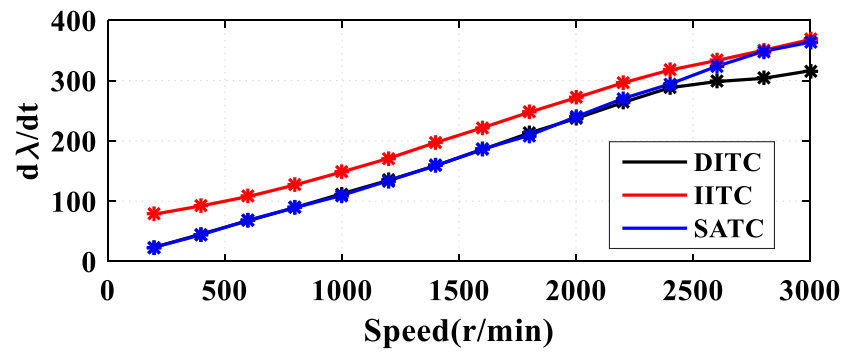

(f)

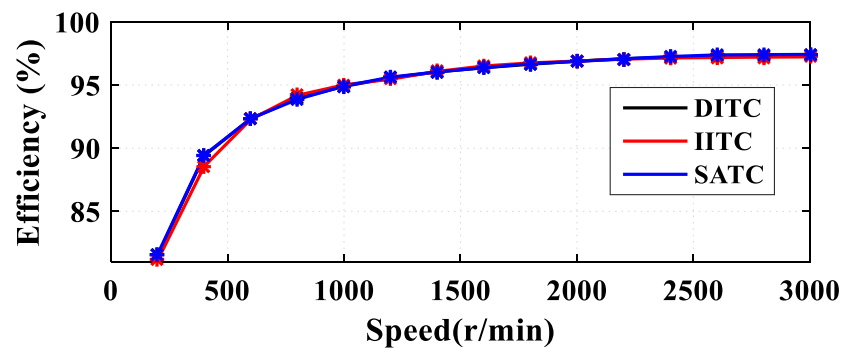

(g)
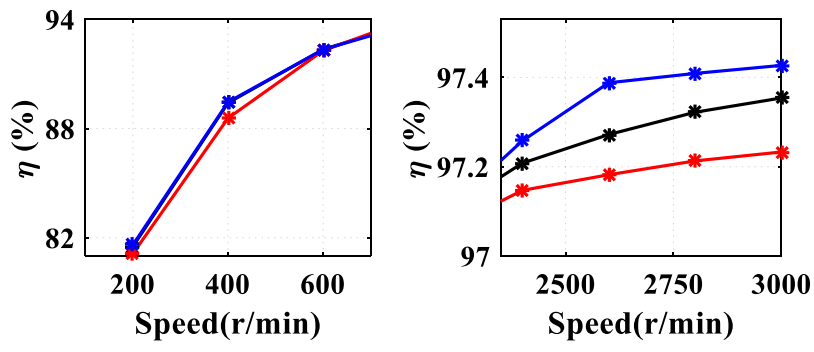

(h)

Figure 11. The steady-state characteristics under electric vehicle (EV) loading-(a) average torque, (b) torque ripple, (c) torque per current ratio, (d)switching frequency, (e) THD, (f) flux derivatives, (g) efficiency, and (h) zoom on efficiency.

\subsection{Dynamic Torque Response}

The dynamic torque performance of the three control techniques is illustrated in Figure 14. The control techniques are tested with a sudden change in reference torque signal from $5 \mathrm{Nm}$ to $20 \mathrm{Nm}$ at $0.05 \mathrm{sec}$. The DITC and IITC techniques have a fast dynamic response. The ATC shows a slower torque response, but still acceptable because it employs a PI controller that outputs reference current. 


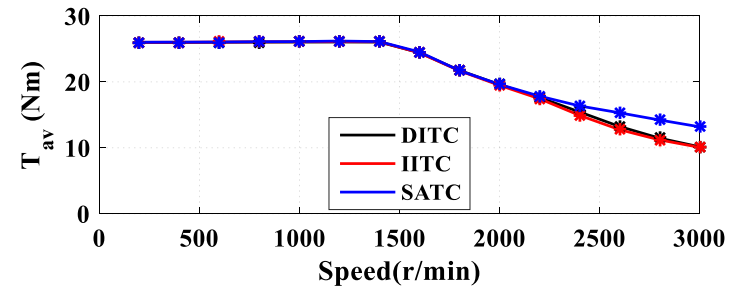

(a)

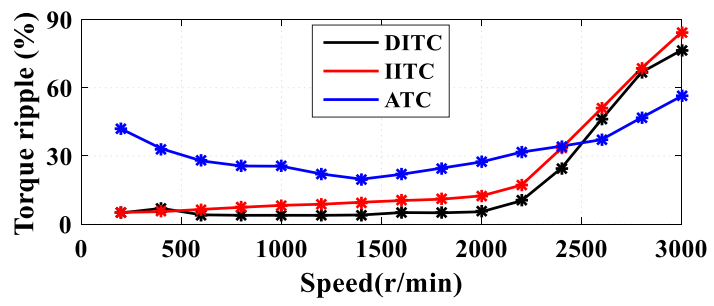

(b)

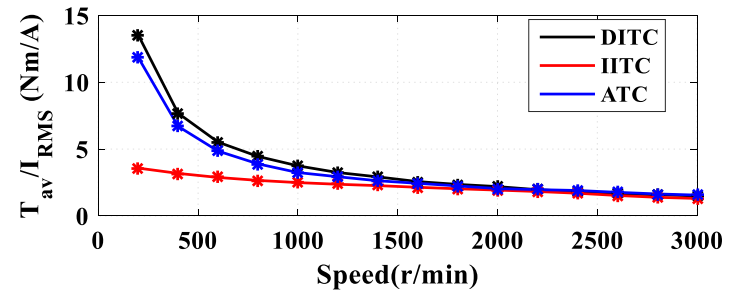

(c)

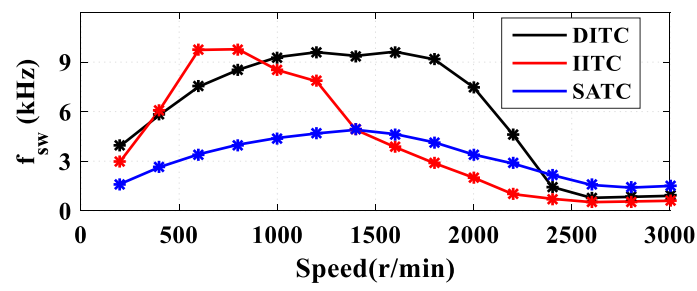

(d)

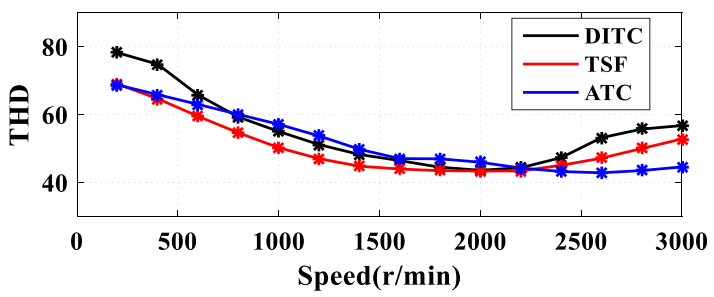

(e)

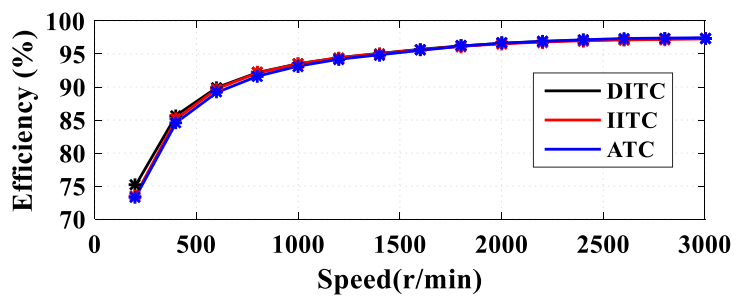

(f)

Figure 12. The steady-state characteristics under EV loading-(a) average torque, (b) torque ripple, (c) torque per current ratio, (d) switching frequency, (e) total harmonic distortion (THD), and (f) efficiency.

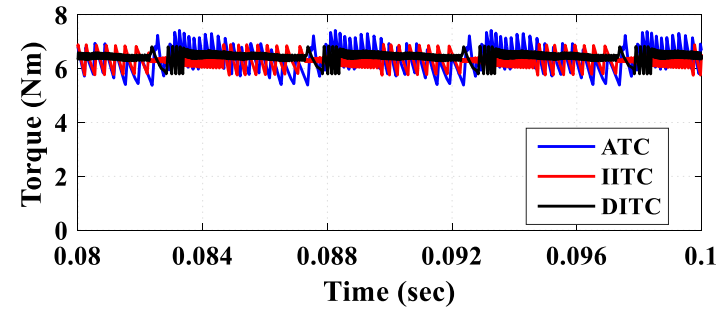

(a)

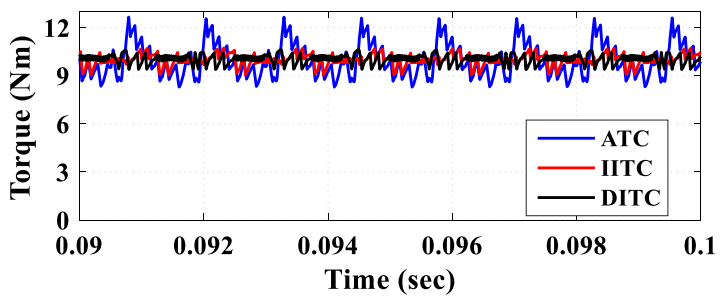

(c)

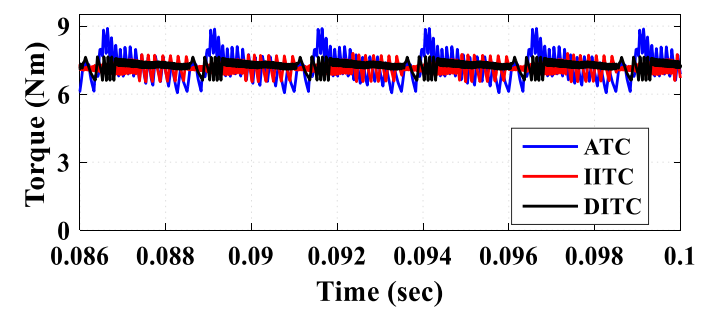

(b)

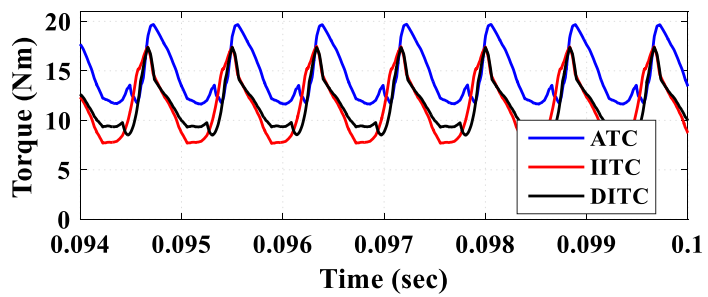

(d)

Figure 13. The torque curves at speed of (a) $500 \mathrm{r} / \mathrm{min}$, (b) $1000 \mathrm{r} / \mathrm{min}$, (c) $2000 \mathrm{r} / \mathrm{min}$, and (d) $3000 \mathrm{r} / \mathrm{min}$. 


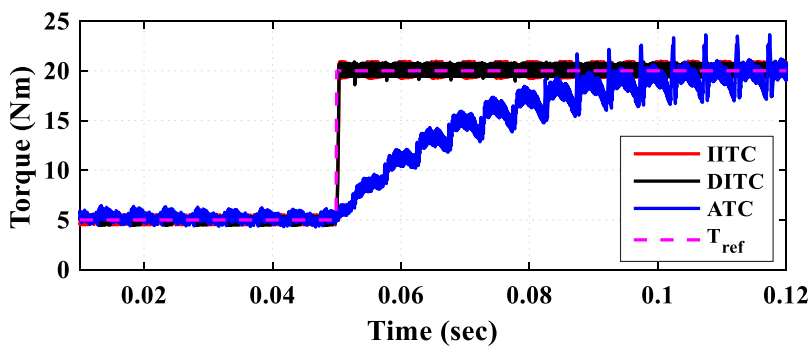

(a)

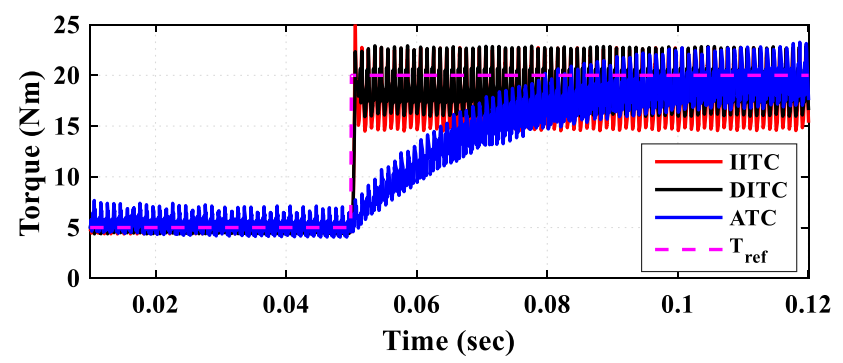

(b)

Figure 14. The dynamic torque curves at speed of (a) $500 \mathrm{r} / \mathrm{min}$ and (b) $2500 \mathrm{r} / \mathrm{min}$.

\section{Summary}

Tables 1 and 2 show the detailed conclusion for the comparative study. As concluded from Table 1, the DITC shows the best overall performance because it has a less complex control algorithm, does not have a torque inverse model, provides a fast dynamic torque response, and has a dynamic torque response, which is the requirement of torque inverse model.

Table 1. Summary of comparison results.

\begin{tabular}{cccc}
\hline Indices & & Low Speed & \\
\cline { 2 - 4 } & DITC & IITC & ATC \\
\hline Algorithm complexity & Moderate & Complex & Complex \\
Requirement of torque inverse model & No & Yes & No \\
Dynamic torque response & Fast & Fast & Slow \\
Requirement of online torque estimation & Yes & Yes & Yes \\
Required control period & Short & Short & Long \\
\hline
\end{tabular}

Table 2. Summary of comparison results over speed ranges.

\begin{tabular}{ccccccc}
\hline \multirow{2}{*}{ Indices } & \multicolumn{3}{c}{ Low Speed } & \multicolumn{3}{c}{ High Speed } \\
\cline { 2 - 7 } & DITC & IITC & ATC & DITC & IITC & ATC \\
\hline Average torque & High & High & High & Low & Low & High \\
Torque ripple & Low & Medium & High & Medium & Medium & Low \\
Switching frequency & High & Medium & Low & Medium & Low & High \\
Torque/current ratio & High & Low & Medium & High & Low & High \\
THD & Medium & Low & High & High & Medium & Low \\
Flux derivatives & Low & High & Low & Low & High & High \\
Efficiency & High & Medium & High & Medium & Medium & High \\
\hline
\end{tabular}

Table 2 provides a comparison regarding the peed ranges. In conclusion, for low speeds, the DITC provides the lowest torque, the highest torque/current ratio, the lowest flux derivatives, and the highest efficiency. However, it has a moderate value for the THD of phase current; it also has a higher switching frequency $(<10 \mathrm{kHz})$ but still within the applicable range.

On the other hand, for high speeds, the ATC can provide high average torque production. It also shows the minimum torque ripple. Moreover, it has the highest torque/current ratio, the lower THD of phase current, and the highest efficiency. However, it has a higher switching frequency and higher flux derivatives.

\section{Conclusions}

This paper presents an improved DITC of SRM drives for EVs. The main concern is to satisfy the vehicle requirements including MTPA, minimum torque ripple, wide speed range, and high efficiency. First, the turn-on angle was estimated analytically to provide the MTPA conditions. Second, an optimization-based method was used to estimate the 
optimum turn-off angles that provide the lowest torque ripple, the lowest copper losses, and the highest efficiency. In addition, the proposed DITC compensates for the torque error to provide a lower torque ripple with extended speed operation. A torque-to-current conversion was conducted using the FEM-calculated torque data. Moreover, the IITC and the ATC techniques were implemented and compared to the proposed DITC. The results show the superior performance of the proposed DITC. As noted, the DITC can provide the lowest torque ripple, the highest torque to current ratio, and the best efficiency over the low and medium speed ranges. Moreover, the comparison presents a very good perspective to develop a universal control technique of SRM drives for EVs. This paper recommends a universal control that uses the proposed DITC over the low speeds and utilizes the ATC for the high speeds.

Author Contributions: Conceptualization, M.H.; Formal analysis, M.H.; Investigation, M.H. and M.N.I.; Methodology, M.H.; Project administration, L.S.; Software, M.H., A.A.M., H.R., and M.N.I.; Validation, M.H.; Visualization, H.R. and M.N.I.; Writing-original draft, M.H.; Writing-review and editing, A.A.M., H.R., M.N.I., and L.S. All authors have read and agreed to the published version of the manuscript.

Funding: This research received no external funding.

Conflicts of Interest: The authors declare no conflict of interest.

$\begin{array}{ll}\text { Abbreviations } \\ \text { ATC } & \text { Average torque control } \\ \text { DC } & \text { Direct current } \\ \text { DITC } & \text { Direct instantaneous torque control } \\ \text { DTC } & \text { Direct torque control } \\ \text { EVs } & \text { Electric vehicles } \\ \text { FEA } & \text { finite element analysis (FEA) } \\ \text { IITC } & \text { Indirect instantaneous torque control } \\ \text { ITC } & \text { Instantaneous torque control } \\ \text { MTPA } & \text { Maximum torque per ampere } \\ \text { PMs } & \text { Permanent magnets } \\ \text { RMS } & \text { Root Mean Square } \\ \text { SRM } & \text { Switched reluctance motor } \\ \text { THD } & \text { Total harmonic distortion } \\ \text { TSF } & \text { Torque sharing function }\end{array}$

\section{References}

1. Chen, H.; Yan, W.; Gu, J.; Sun, M. Multiobjective Optimization Design of a Switched Reluctance Motor for Low-Speed Electric Vehicles with a Taguchi-CSO Algorithm. IEEE/ASME Trans. Mechatron. 2018, 23, 1762-1774. [CrossRef]

2. Yueying, Z.; Chuantian, Y.; Yuan, Y.; Weiyan, W.; Chengwen, Z.; Zhu, Y.; Yang, C.; Yue, Y.; Wei, W.; Zhao, C. Design and optimisation of an In-wheel switched reluctance motor for electric vehicles. IET Intell. Transp. Syst. 2019, 13, 175-182. [CrossRef]

3. Jiang, J.W.; Bilgin, B.; Emadi, A. Three-Phase 24/16 Switched Reluctance Machine for a Hybrid Electric Powertrain. IEEE Trans. Transp. Electrif. 2017, 3, 76-85. [CrossRef]

4. Zhu, J.; Cheng, K.W.E.; Xue, X. Design and Analysis of a New Enhanced Torque Hybrid Switched Reluctance Motor. IEEE Trans. Energy Convers. 2018, 33, 1965-1977. [CrossRef]

5. Bartolo, J.B.; Degano, M.; Espina, J.; Gerada, C. Design and Initial Testing of a High-Speed 45-kW Switched Reluctance Drive for Aerospace Application. IEEE Trans. Ind. Electron. 2017, 64, 988-997. [CrossRef]

6. Mousavi-Aghdam, S.R.; Feyzi, M.R.; Bianchi, N.; Morandin, M. Design and Analysis of a Novel High-Torque Stator-Segmented SRM. IEEE Trans. Ind. Electron. 2016, 63, 1458-1466. [CrossRef]

7. Nam, K.H. AC Motor Control and Electrical Vehicle Applications; CRC Press Taylor \& Francis Group: Boca Raton, FL, USA, 2019.

8. Ehsani, M.; Gao, Y.; Emadi, A. Modern Electric, Hybrid Electric, and Fuel Cell Vehicles: Fundamentals, Theory, and Design; CRC Press: Boca Raton, FL, USA, 2010.

9. Husain, T.; Elrayyah, A.; Sozer, Y.; Husain, I. Unified Control for Switched Reluctance Motors for Wide Speed Operation. IEEE Trans. Ind. Electron. 2019, 66, 3401-3411. [CrossRef] 
10. Husain, T.; Elrayyah, A.; Sozer, Y.; Husain, I. An efficient universal controller for switched-reluctance machines. In Proceedings of the 2013 28th Annual IEEE Applied Power Electronics Conference and Exposition (APEC), Long Beach, CA, USA, 17-21 March 2013; pp. 1530-1536.

11. Gan, C.; Wu, J.; Sun, Q.; Kong, W.; Li, H.; Hu, Y. A Review on Machine Topologies and Control Techniques for Low-Noise Switched Reluctance Motors in Electric Vehicle Applications. IEEE Access 2018, 6, 31430-31443. [CrossRef]

12. Mikail, R.; Husain, I.; Sozer, Y.; Islam, M.S.; Sebastian, T. Torque-Ripple Minimization of Switched Reluctance Machines Through Current Profiling. IEEE Trans. Ind. Appl. 2013, 49, 1258-1267. [CrossRef]

13. Shaked, N.; Rabinovici, R. New procedures for minimizing the torque ripple in switched reluctance motors by optimizing the phase-current profile. IEEE Trans. Magn. 2005, 41, 1184-1192. [CrossRef]

14. Ye, J.; Bilgin, B.; Emadi, A. An Offline Torque Sharing Function for Torque Ripple Reduction in Switched Reluctance Motor Drives. IEEE Trans. Energy Convers. 2015, 30, 726-735. [CrossRef]

15. Ye, J.; Bilgin, B.; Emadi, A. An Extended-Speed Low-Ripple Torque Control of Switched Reluctance Motor Drives. IEEE Trans. Power Electron. 2015, 30, 1457-1470. [CrossRef]

16. Suebsuang, P.J.S. An adaptive low-ripple torque control of switched reluctance motor for small electric vehicle. In Proceedings of the International Conference on Electrical Machines and Systems, Wuhan, China, 17-20 October 2008; pp. 3327-3332.

17. Chithrabhanu, A.; Vasudevan, K. Online compensation for torque ripple reduction in SRM drives. In Proceedings of the IEEE Transportation Electrification Conference (ITEC-India), Chicago, IL, USA, 22-24 June 2017; pp. 1-6.

18. Shirahase, M.; Morimoto, S.; Sanada, M. Torque ripple reduction of SRM by optimization of current reference. In Proceedings of the International Power Electronics Conference-ECCE ASIA, Sapporo, Japan, 21-24 June 2010; pp. 2501-2507.

19. Nasirian, V.; Kaboli, S.; Davoudi, A.; Moayedi, S. High-Fidelity Magnetic Characterization and Analytical Model Development for Switched Reluctance Machines. IEEE Trans. Magn. 2012, 49, 1505-1515. [CrossRef]

20. Hamouda, M.; Szamel, L. Torque Control of Switched Reluctance Motor Drives for Electric Vehicles. In Proceedings of the Automation and Applied Computer Science Workshop, Budapest, Hungary, 16 June 2017; pp. 9-20.

21. Jamil, M.U.; Kongprawechnon, W.; Chayopitak, N. Average Torque Control of a Switched Reluctance Motor Drive for Light Electric Vehicle Applications. IFAC PapersOnLine 2017, 50, 11535-11540. [CrossRef]

22. Cheng, H.; Chen, H.; Yang, Z. Average torque control of switched reluctance machine drives for electric vehicles. IET Electr. Power Appl. 2015, 9, 459-468. [CrossRef]

23. Petrus, V.; Pop, V.; Gyselinck, A.-C.; Martis, J.; Iancu, C. Average Torque Control of an 8/6 Switched Reluctance Machine for Electric Vehicle Traction. J. Comput. Sci. Control Syst. 2012, 5, 59.

24. Bose, B.K.; Miller, T.J.E.; Szczesny, P.M.; Bicknell, W.H. Microcomputer Control of Switched Reluctance Motor. IEEE Trans. Ind. Appl. 1986, 22, 708-715. [CrossRef]

25. Xue, X.D.; Cheng, K.W.E.; Lin, J.K.; Zhang, Z.; Luk, K.F.; Ng, T.W.; Cheung, N.C. Optimal Control Method of Motoring Operation for SRM Drives in Electric Vehicles. IEEE Trans. Veh. Technol. 2010, 59, 1191-1204. [CrossRef]

26. Nguyen, D.-M.; Bahri, I.; Krebs, G.; Berthelot, E.; Marchand, C.; Ralev, I.V.; Burkhart, B.; De Doncker, R.W. Efficiency Improvement by the Intermittent Control for Switched Reluctance Machine in Automotive Application. IEEE Trans. Ind. Appl. 2019, 55, 4167-4182. [CrossRef]

27. Inderka, R.; De Doncker, R. DITC-direct instantaneous torque control of switched reluctance drives. IEEE Trans. Ind. Appl. 2003, 39, 1046-1051. [CrossRef]

28. Fuengwarodsakul, N.; Menne, M.; Inderka, R.; De Doncker, R. High-Dynamic Four-Quadrant Switched Reluctance Drive Based on DITC. IEEE Trans. Ind. Appl. 2005, 41, 1232-1242. [CrossRef]

29. Chancharoensook, P. Direct instantaneous torque control of a four-phase switched reluctance motor. In Proceedings of the International Conference on Power Electronics and Drive Systems (PEDS), Taipei, Taiwan, 2-5 November 2009; pp. 770-777.

30. Castro, J.; Andrada, P.; Blanqué, B. Minimization of torque ripple in switched reluctance motor drives using an enhanced direct instantaneous torque control. In Proceedings of the XXth International Conference on Electrical Machines, Marseille, France, 2-5 September 2012; pp. 1021-1026.

31. Kianinezhad, M.M.B.M.S.R. Direct Instantaneous Torque Control of Switched Reluctance Motors Using Five Level Converter. In Proceedings of the 46th International Universities Power Engineering Conference, Soest, Germany, 5-8 September 2011.

32. Yang, Q.; Ma, M.; Chang, Z.; Zhang, X.; Lin, Z. Direct instantaneous torque control of switched reluctance motor with three-bridge five-level converter. PEMD 2016, 2016, 574. [CrossRef]

33. Song, S.; Peng, C.; Guo, Z.; Ma, R.; Liu, W. Direct Instantaneous Torque Control of Switched Reluctance Machine Based on Modular Multi-Level Power Converter. In Proceedings of the 22nd International Conference on Electrical Machines and Systems (ICEMS), Harbin, China, 11-14 August 2019.

34. Sun, Q.; Wu, J.; Gan, C. Optimized Direct Instantaneous Torque Control for SRMs with Efficiency Improvement. IEEE Trans. Ind. Electron. 2020, 68, 1. [CrossRef]

35. Sandre-Hernandez, O.; Rangel-Magdaleno, J.D.J.; Morales-Caporal, R. A Comparison on Finite-Set Model Predictive Torque Control Schemes for PMSMs. IEEE Trans. Power Electron. 2018, 33, 8838-8847. [CrossRef] 
36. Hamouda, M.; Számel, L. Accurate Magnetic Characterization Based Model Development for Switched Reluctance Machine. Period. Polytech. Electr. Eng. Comput. Sci. 2019, 63, 202-212. [CrossRef]

37. Hamouda, M.; Számel, L. A new technique for optimum excitation of switched reluctance motor drives over a wide speed range. Turk. J. Electr. Eng. Comput. Sci. 2018, 26, 2753-2767. [CrossRef] 